\title{
As concepções de estado e as influências do neoliberalismo na política educacional
}

\author{
Clícia Bührer Martins ${ }^{1}$ \\ Maria das Graças do Espirito Santo Tigre ${ }^{1}$ \\ Maria Odete Vieira Tenreiro ${ }^{1}$ \\ Marisete Mazurek Tebcherani ${ }^{1}$
}

RESUMO

Procurou-se realizar um estudo teórico a respeito das diferentes concepções de Estado do papel que este foi assumindo em cada contexto histórico, enfocando as formas de organização da sociedade, as questões de poder, democracia e subordinação, bem como suas influências na educação brasileira. Um destaque especial foi dado ao Estado Neoliberal e suas implicações na política educacional atual.

Palavras-chave: teorias de Estado, política educacional, neoliberalismo

\section{Introdução}

A pretensão deste trabalho é desenvolver uma análise teórica sobre a validade social e política das diferentes formas de Estado, enquanto processo e produto do sistema educacional.
O estudo sobre o papel do Estado no mundo moderno até os dias atuais é significativo, pois permitirá mostrar que suas transformações acompanharam as da sociedade civil. Nesse percurso, as teorias políticas e algumas relações sociais mais expressivas

\footnotetext{
${ }^{1}$ Alunas do Curso de Mestrado em Educação da Universidade Estadual de Ponta Grossa, disciplina de Política Educacional, ministrada pela Prof ${ }^{a}$ Dra. Rosilda Baron Martins, no $1^{\circ}$ semestre de 1999.

Olhar de professor, Ponta Grossa, 2 (2):9-30, nov. 1999.
} 
que determinaram as práticas dos agentes coletivos serão investigadas através dos processos que provocaram tais modificações, o que torna possível uma reflexão sobre os sistemas de governo e a realidade educacional.

A compreensão do Estado como poder político organizado no interior da sociedade civil, que exerce um controle quase total sobre a vida das pessoas, requer necessariamente o conhecimento da sociedade. Como a vida em sociedade se acha permeada por esse organismo político que cada vez mais amplia o seu alcance, objetiva-se apresentar os fundamentos clássicos das teorias de Estado Absolutista, Estado Liberal e Estado de Bem-Estar Social e descobrir as idéias centrais de que se servem os neoliberais para formular os princípios teóricos de seu programa de execução.

O Neoliberalismo é uma teoria de alcance prático e universal, e seu programa de ação consiste em fazer do mercado a única instância em que os problemas da humanidade podem ser resolvidos, tornando-se por isso um credo mundial abraçado por quase todos os países.

Nessa perspectiva, acredita-se que buscar os princípios filosóficos que lhe dão sustentação e legitimidade político-ideológica servirá de base para a elucidação das políticas sociais, entre estas mais especificamente a educacional.

As especulações que fazem parte do cotidiano brasileiro e paranaense incluem o Estado em alguma de suas manifestações, de modo central ou tangencial. É quase habitual sentir a proximidade dessa questão, seja pela presença ou ausência do Estado em áreas fundamentais da vida em sociedade, seja porque existe na sociedade toda distintos níveis de disseminação sobre o que é o Estado e o seu papel, a propósito da onda "neoliberal" que caracteriza o final da década de 80 e 90.

\section{Política e Estado Moderno}

Ninguém, em tempo algum, chegou a ver um Estado. Nem a olho nu nem ao microscópio, nem em fotografia nem em avião. Não é uma coisa, como um território ou uma porção do oceano mas uma certa relação entre os homens pelo qual o direito de comandar é independente da pessoa do comandante. Uma coletividade é regida por um Estado quando o vínculo de submissão de homem a homem é substituído por uma subordinação de princípio (DEBRAY, 1994, p.61).

Essa citação remete à concepção de que a política refere-se à ação dos governantes que detêm a autoridade para dirigir a coletividade organizada em Estado. As ações dessa coletividade podem ser de apoio ou contrárias às decisões governamentais e à organização estatal .

A forma de organização da socie- 
dade deve se fazer por profissionais, administradores e especialistas que se ocupam exclusivamente com o Estado e com as questões de poder. Assim, dependendo do uso do exercício de poder, este pode ser voltado à submissão dos participantes da coletividade, inserindo-se aí a tecnocracia, ou seja, o poder das elites, ou à participação da sociedade como um todo, voltada então à democracia.

A política é de subordinação, conforme nos afirma Chauí, quando "é feita 'por eles' e não 'por nós,' ainda que 'eles' se apresentem como representantes 'nossos"' (1995, p. 369).

Na condição democrática, os dirigentes devem adaptar sua forma de governo às necessidades do povo. A legitimidade da democracia é estabelecida quando os cidadãos passam a ser sujeitos de seus direitos, tendo a prerrogativa de lutar por eles e exigi-los quando seu exercício não lhes for assegurado. Assim, uma sociedade é considerada democrática quando os direitos são instituídos e legitimados em respeito à vontade da maioria e das minorias.

É possível falar, segundo Dagnino (1994), numa redefinição da idéia de direitos, cujo ponto de partida é a concepção de um direito a ter direitos.

O Estado Moderno ${ }^{2}$ é relativamente recente e a primeira forma a ser dele destacada é o Estado Absolutista.

\subsection{O Estado Absolutista}

O Absolutismo é conseqüência de um extenso processo histórico que teve início com a crise da sociedade feudal e que veio a constituir a burguesia na Europa Ocidental, a partir do século XIV.

Essa nova classe procurou estabelecer alianças políticas com os monarcas. A monarquia e a burguesia acabaram por centralizar as decisões políticas, estendendo a sua força por vários territórios que antes eram administrados pelos senhores feudais.

A formação dos Estados Absolutistas não ocorreu de forma pacífica. Esse período histórico do mundo capitalista é assinalado por fortes conflitos entre aristocracia e burguesia, sociedade civil e Estado, católicos e protestantes.

O mais significativo representante teórico do Estado Absolutista foi Thomas Hobbes ${ }^{3}$ (1588-1679). Ele

\footnotetext{
${ }^{2}$ A aparição do Estado Moderno na história da humanidade, como idéia moderna de um Estado Democrático, tem suas raízes no século XVIII, envolvendo certos valores fundamentais da pessoa humana, bem como a exigência de organização e funcionamento do Estado, tendo em vista a proteção daqueles valores. Nasceu das lutas contra o Absolutismo, sobretudo através da afirmação dos direitos naturais da pessoa humana (Cf. CARNOY, 1986).

${ }^{3}$ Sobre Thomas Hobbes ver Leviatã ou Matéria, Forma e Poder de um Estado Eclesiático e Civil, 1988 .
} 
admitia que o homem apesar de viver em sociedade, não possui o instinto natural de sociabilidade. As pessoas só passam a viver em sociedade diante de uma ameaça à preservação da vida. Segundo Aranha,

a situação dos homens deixados a si próprios é de anarquia, geradora de insegurança, angústia e medo. Os interesses egoístas predominam, eo homem se torna o lobo para o outro homem (1987, p.241).

Nesse sentido, cada homem encara seu semelhante como um concorrente que precisa ser dominado. Para dar fim à brutalidade social primitiva, o homem deve abdicar de seus direitos em favor do soberano, que terá um poder absoluto; e esse poder será exercido pela força da sociedade política artificial, administrada pelo Estado. Assim, cabe ao soberano julgar a liberdade de seus súditos e permitir-lhes ações como: comprar, vender ou realizar contratos mútuos ou, ainda, cada um escolher a sua residência, alimentação, profissão e instrução dos filhos. O Estado, por conseguinte, reduz-se-à garantia dos interesses particulares, tendo o poder de prescrever as leis, fazer a guerra e a paz, recompensar e punir, escolher seus conselheiros.

O Estado Absolutista preencheu uma parcela de sua administração com cargos ocupados pela nobreza, uma vez que entendia que a função de seus membros se diferenciava das atividades de interesse particular. Também apresentou o papel de interventor no controle da economia, sendo o principal responsável pela construção manufatureira naquela época, da mesma forma que impôs funções complexas e especializadas, aprofundando seu controle sobre bens e pessoas. Conforme Ferreira,

para dar conta dessas novas atividades, a monarquia absolutista desenvolveu um importante componente de sua estrutura - o Judiciário. Com a revalorização do antigo direito romano, o que era público ou privado ficou mais bem delineado (1993, p.130).

Portanto, assemelhado a um Estado burguês, o Estado Absolutista foi responsável pelas medidas econômicas e políticas, fundamentais ao avanço da chamada acumulação primitiva do capital.

Nos dias atuais, quando se admite que o bem público é um bem de todos, não podendo ser de ninguém em particular, retrata-se a distinção clara entre público e privado que começou a ser estabelecida com o Estado Absolutista.

O resultado dessa concepção política no âmbito educacional traduzse na formação de indivíduos voltados para um ensino baseado em princípios religiosos e políticos. Os projetos educacionais da monarquia não superam os limites de sua concepção de poder e manifestam-se como prática assistencialista. 
Desde o período Absolutista até a Revolução Francesa de 1789, o objetivo da educação estatal era formar o cidadão na pessoa do súdito. O ensino para as camadas populares ficava limitado aos elementos mais rudimentares.

Quanto ao conteúdo que a escola ministrava, era parte de uma concepção de mundo que expressava basicamente os interesses da classe dominante.

\subsection{O Estado Liberal}

O pensamento liberal surgiu numa época de profundas modificações político-econômicas ocorridas na Europa durante o século XVII e XVIII, as quais consolidaram-se com os acontecimentos de 1789, na França, trazendo uma série de reflexões teóricas a respeito do papel do Estado. Contra o absolutismo real, o Estado Liberal vem buscar nas teorias contratualistas as formas de legitimação do poder, não mais fundado no direito divino dos reis, mas no consentimento dos cidadãos. Assim, para que a sociedade burguesa instituisse o mercado livre era preciso estabelecer a separação mais nítida entre o que era público e o que era privado.

O Estado Liberal não se caracteriza somente como um mero protetor da propriedade privada capitalista. Uma de suas funções é captar recursos para garantir a manutenção do sis- tema social e o investimento no desenvolvimento econômico. Apresenta-se, assim, como representante do público e guardião do privado.

Com a ampliação e o fortalecimento do poder econômico na estrutura do Estado, a burguesia acabou por romper com a monarquia absolutista. Entretanto, apesar da burguesia liberal do século XVIII requerer uma ampla liberdade nas atividades econômicas, não tirava o poder político do Estado, de cuja intervenção necessitava para assuntos que envolvessem a repressão da classe operária em suas reivindicações.

O Estado liberal burguês introduziu uma nova dimensão de legitimidade: a igualdade passa pela ampliação dos direitos políticos dos cidadãos, apresentadas como o meio de garantir a participação no poder e o seu controle, baseado e organizado na forma de uma democracia. Com base nessas considerações, John Locke ${ }^{3}$ (1632-1704) admite que

as condições para liberdade e igualdade entre os individuos estavam dadas na sociedade civil, ao Estado caberia proteger tal situação (...). Deve o Estado Liberal zelar pela segurança de todos, pela segurança pública, protegendo os indivíduos contra medidas e atos que possam subverter seus

\footnotetext{
${ }^{3}$ Para um maior aprofundamento sobre as idéias de John Locke, ver ensaio acerca do entendimento humano, segundo tratado sobre o governo, 1991.
} 
direitos inalienáveis (FERREIRA, 1993, p.133).

Nesse contexto o poder político liberal deixa de ser hereditário, como ocorria no Absolutismo, bem como não deve intervir, mas sim garantir e tutelar o livre exercício da propriedade, da palavra e da iniciativa econômica.

Dessa forma, o Liberalismo concebe o homem como naturalmente livre. Com as idéias de direito natural dos indivíduos e de sociedade civil quebra-se a idéia de hierarquia. Locke afirma que, embora a terra e todas as criaturas inferiores pertençam em comum a todos os homens, cada um conserva a propriedade de sua própria pessoa, ou seja, todo homem é proprietário de si mesmo e de suas capacidades. O trabalho do seu corpo é propriamente dele; portanto, o trabalho dá início ao direito de propriedade em sentido estrito (bens e patrimônio). Na teoria de Locke, mesmo quem não possui bens é proprietário de sua vida, de seu corpo e de seu trabalho.

A concepção de Locke remete a um discurso ambigüo, quando se considera que no Estado moderno existem as desigualdades sociais. Assim, a liberdade de cada indivíduo está limitada à sua condição de classe e de posse. Com isso, a plena cidadania, que é a base necessária para a efetiva participação na sociedade civil, é restrita àqueles que se enquadram na condição de proprietários, considerados os únicos integralmente capazes de vida racional. A plena cidadania presente na raiz do Liberalismo é, pois, de uma natureza abstrata e puramente formal.

Para Locke, o papel do Estado é institucionalizar os direitos e deveres a serem cumpridos na sociedade, através da organização dos indivíduos livres, para os quais, o fundamento da liberdade no plano político estaria atrelada ao plano econômico.

Incluindo-se nessa corrente liberal, Adam Smith (1723-1790) preconiza que os indivíduos são livres para buscar a realização do seu bem estar social, especialmente pela via do jogo livre da oferta e da procura do mercado (laissez faire). Como o Estado não deve intervir nem na indústria nem no comércio, o mercado seria regulado por uma "mão invisível” naturalmente justa, que controlaria paixões e desejos individuais (qualidade, quantidade e preços), lançando a base para a construção do bem comum. O autor condena toda forma de ingerência do Estado na economia, admitindo a sua intervenção em apenas três situações: na defesa do território, na garantia da propriedade privada e na execução de obras públicas ${ }^{4}$.

\footnotetext{
${ }^{4}$ Para um maior aprofundamento sobre o papel do Estado defendido por Adam Smith, ver Uma investigação sobre a natureza e causas da riqueza das nações, 1986.
} 
Outro defensor da teoria liberal é Jean Jacques Rousseau (1712-1778), que concebe o Estado como instituição para dar equilíbrio a uma forma de convivência em que os homens nascidos livres renunciariam seus direitos naturais em prol de uma vontade geral. Para ele, "o fundamento do poder político é o pacto social pelo qual cada cidadão, como membro de um povo, concorda em submeter sua vontade particular à vontade geral" (COTRIM, 1997, p.243). Respeitar as leis, obedecer à vontade geral é respeitar a si mesmo, sua própria vontade como cidadão, cujo interesse deve ser o bem comum. Desta forma, todas as relações sociais baseadas nas aspirações humanas fazem parte dos direitos naturais que pertencem ao homem ${ }^{5}$.

Apesar de defender o pensamento liberal, Rousseau ultrapassa o Absolutismo Lockeano e propõe uma visão mais democrática de poder, não apresentando uma idéia revolucionária. Em seu discurso sobre a desigualdade entre os homens, Rousseau concebe na espécie humana duas espécies de desigualdade: uma chamada de natural ou física, que consiste na diferença de idades, de saúde, das forças do corpo e das qualidades do espírito ou da alma; a outra, chamada de desigualdade moral ou política, refere-se aos diferentes privilégios que alguns possuem em prejuízo dos outros, por serem mais ricos, por terem mais honrarias, por serem mais poderosos.

Na busca de solução para a desigualdade entre os homens, Rousseau propõe o contrato social, que para ser legítimo deve se originar do consentimento necessariamente unânime. Para ele,

a desigualdade entre os homens torna necessária a existência do Estado, onde cada indivíduo cede à comunidade os seus direitos naturais, e recebe em troca os direitos civis, ou seja, a todos será assegurada a liberdade, e ninguém será súdito de ninguém, mas o Estado se torna, assim, a síntese das liberdades individuais (NIELSEN NETO, 1986, p. 251).

Quanto aos reflexos dessa concepção que prioriza a liberdade e a individualidade, a escola deve estimular as características inatas do indivíduo, para que ele possa em sociedade desempenhar o papel que lhe cabe na estrutura social. O papel da escola é garantir a todos a possibilidade de ascensão social, oferecendo aos alunos igual oportunidade de estudos.

No que diz respeito à questão educacional, a escola não deveria atender os interesses de uma classe. O princípio da igualdade social e o respeito às diferenças de classes são

${ }^{5}$ Ver Jean Jacques Rosseau, Do contrato social, 1973. 
produtos da concepção liberal. A escola volta-se, assim, aos princípios da laicidade e gratuidade, com tendências para a ampliação e atendimento da maioria da população.

No Brasil, essa preocupação aparece teoricamente no Manifesto dos Pioneiros $^{6}$ (1932) e os pressupostos anunciados pelos educadores que o lideraram são extensivos a todas as instituições oficiais, embora muitas vezes desrespeitados na prática.

\subsection{Estado de Bem Estar Social}

A concepção de "Estado de Bem Estar" começou a ser introduzida em meados da década de 40, na Europa. Ela surge das idéias do economista inglês John Maynard Keynes (18831946), como uma contestação ao Liberalismo, que proporcionou uma série de crises permeadas pelo desenvolvimento industrial, revolucionando as relações de produção. Nesse enfoque, criticavam-se as enormes concentrações de riqueza, a apropriação do direito natural, a complexificação das economias, a falta de mecanismos reguladores para a dinâmica, que evidenciavam o mau funcionamento na estrutura global, culminando com a depressão de 1929.
Keynes sugeria o desenvolvimento da política de pleno emprego, uma economia planejada que levasse a uma maior estabilidade, a redistribuição de renda em favor dos trabalhadores e o incentivo à especulação financeira, reduzindo as taxas de juros, entre outras medidas ${ }^{7}$.

$\mathrm{Na}$ opinião de Keynes, o Estado deveria assumir o papel de interventor da política fiscal "como instrumento de redistribuição direta, ou como suporte financeiro para a criação de aparelhos de consumo coletivo" (LOPES, 1995, p.3). Assim, são incorporados como direitos de cidadania: educação, saúde, transporte e habitação.

O período pós-guerra se caracteriza propício para introduzir esse novo paradigma, quer pela necessidade de se gerar instrumentos estabilizadores da economia, quer pela necessidade de criar mecanismos de gestão com base no referencial intelectual marxista e pós-marxista.

Marx apresentou contribuições significativas, ao mostrar as raízes das desigualdades sociais e da exploração inerentes às sociedades de classe. Nessa ótica abordou as políticas sociais quase inexistentes no seu tempo. Sua intenção era encontrar meios para a mais ampla condição de igual-

${ }^{6}$ O Manifesto dos Pioneiros da Educação Nova foi liderado por Fernando de Azevedo e por mais 26 educadores. O documento considerava dever do Estado tornar a educação obrigatória, pública, gratuita e leiga. O Movimento representou, na época, o pensamento de "reconstrução educacional".

${ }^{7}$ Ver John Maynard Keynes, A teoria geral do emprego, do juro e da moeda, inflação e eflação, 1985. 
dade e bem-estar dos seres humanos.

Marx e Engels, coincidentemente, fundamentaram uma teoria de Estado combinando na determinação de alguns postulados, dentre eles, que o Estado Capitalista é a expressão política de estrutura de classes inerentes à produção. Desde que a burguesia, na produção capitalista, tem um controle particular da mão-de-obra no processo de produção, ela também estende sua relação de poder ao Estado e a outras instituições sociais. Marx, diferenciando-se de Engels, argumentava que o Estado, emergindo da relação de produção, não representa o bem comum, mas é a expressão política da classe dominante. O Estado Capitalista é uma resposta à necessidade de mediar o conflito de classe e manter a ordem; uma ordem que reproduz o domínio econômico da burguesia $^{8}$.

O Estado é um aparelho repressivo da burguesia, que objetiva legitimar o poder, reprimir, reforçar a reprodução da estrutura e das relações de classe.

A importância da escola básica é questionada por Marx e Engels, que referenciam a educação como um dos instrumentos de apoio na organização e na luta do proletariado contra a burguesia e, também, o papel do Estado burguês como o responsável pela educação popular.

Marx evidenciava que a organiza- ção do mundo do trabalho permitiria a obtenção de conquistas amenizadoras do grau de exploração. Assim, ele ressalta a importância da luta dos trabalhadores para a diminuição da jornada de trabalho e a regulação da mesma pelo Estado. Reconhecia que o poder público, mesmo legislando a favor do trabalho, estaria garantindo, em última instância, as condições gerais da produção e reprodução daquela ordem.

Nesse contexto, Gramsci também tece algumas considerações sobre o conteúdo conteúdo ético do Estado, na medida em que uma de suas funções consiste em elevar a grande massa da população a um certo nível cultural e moral, que corresponde à necessidade de desenvolver as forças produtivas e, portanto, aos interesses das classes dominantes. O Estado não se reduz ao aparelho do Estado (sociedade política), mas compreende, também, a sociedade civil (organizações ditas privadas que são o conteúdo intelectual e moral do Estado). Portanto, o Estado é constituído de sociedade política + sociedade civil.

Offe e Poulantzas apresentam uma análise mais recente a respeito das idéias de Marx e Engels sobre o papel do Estado enquanto interventor e instância encarregada da defesa dos interesses do capital global.

Para Claus Offe (FREITAG, 1987), a função das políticas sociais

\footnotetext{
${ }^{8}$ Cf. DEMO, Pedro. Sociologia: uma introdução crítica. 2 ed. São Paulo: Atlas , 1995.
} 
é transformar toda força de trabalho disponível em força de trabalho assalariada. O Estado Capitalista moderno não só se encarrega de qualificar a força de trabalho para o mercado, como procura controlar, manter, subsidiar e represar os indivíduos que ainda não têm aproveitamento no processo produtivo, deixando-os em estado de prontidão para as necessidades do mercado.

Nas crises do capitalismo, o Estado apresenta-se para Offe como mediador, com funções específicas para atender as contradições da socialização da produção e a apropriação privada da mais-valia. Para exercer essa mediação, vê-se obrigado a expandir suas funções institucionais. O Estado, para Offe,

é um sistema administrativo autorregulado. É a condensação de um conjunto de bases e dispositivos legais e de instituições formais que se cristalizaram historicamente na sociedade capitalista (TORRES, 1999, p.111)

$\mathrm{Na}$ visão desses autores marxistas, o Estado é um instrumento utilizado para intervir na política econômica e social, congelando as condições próprias ao modo de produção capitalista.

Segundo Offe, para cumprir essas funções do Estado, a política educacional busca desenvolver a socialização dos indivíduos para o exercício das diferentes atividades no Estado capitalista. Os sistemas públicos de ensino assumem um caráter obrigatório e universal. A continuidade do trabalho assalariado é garantida, usando-se a regulação estatal como estratégia para a educação. Assim, o beneficiário das ações e políticas sociais do Estado capitalista é o próprio sistema capitalista.

Para Poulantzas, o papel do Estado é manter a unidade e a coesão da formação social, concentrando e sancionando a dominação de classe. As relações de classe é que definem a ligação do Estado com a classe dominante.

Ainda, Poulantzas vê o Estado com funções econômicas (produção) e com funções ideológico-repressivas (reprodução): interfere diretamente na economia como tentativa de resolver as contradições da produção. Em síntese, para esse autor, o Estado é o centro do exercício do poder, mas não possui seu próprio poder.

Nessa perspectiva de Estado interventor, o Estado de Bem Estar Social incentivava a empresa privada através de uma política financeira que previa taxas de juros reduzidas, com o intuito de garantir o pleno emprego. Os trabalhadores em disponibilidade também poderiam ser absorvidos pelas empresas geridas pelo Estado. Como essa medida não era suficiente para eliminar totalmente os trabalhadores em disponibilidade, o Estado oferecia uma ajuda social aos desempregados. Esses benefícios estenderam-se também às instituições oficiais.

No contexto educacional brasilei- 
ro essa política de Estado teve suas implicações diretas nas grandes reformas educacionais ocorridas nas décadas de 60 e 70, através das Leis 5.540/ 68 e 5.692/71, oriundas dos acordos sigilosos entre MEC-USAID, através dos quais o Brasil recebeu assistência técnica e cooperação financeira para a implantação de tais reformas.

O Projeto MEC-USAID assentava-se em três pilares: educação e desenvolvimento, educação e segurança, educação e comunidade. $\mathrm{O}$ seu objetivo era formar profissionais que atendessem às necessidades do país através da criação de mão-de-obra especializada para o mercado em expansão. Nessa época a presença da empresa começa refletir-se nas escolas, que passam a ser estruturadas segundo os ideais de organização, racionalidade, eficiência e objetividade, seguindo o modelo taylorista.

Nas instituições educacionais brasileiras, a partir do início de 1970, as funções especializadas de Orientação Educacional, Supervisão e Administração Escolar passaram a ser exigidas conforme determinação da Lei 5692/71, evidenciando a perspectiva tecnicista.

\subsection{O Estado Neoliberal}

O neoliberalismo nasceu depois da II Guerra Mundial, na Europa e na América do Norte. Constituiu uma reação teórica e política contra o Estado intervencionista e de bem-estar. Seu texto de origem é "O Caminho da Servidão”, de Friedrich Hayek, 1944.
Em 1947, Hayek convocou aqueles que compartilhavam de suas idéias para uma reunião na estação de Mont Pèlerin, na Suíça. É fundada então a sociedade de Mont Pèlerin, cujo propósito era combater o Keynesianismo e o solidarismo vigentes, e preparar as bases de outro tipo de capitalismo, duro e livre de regras para o futuro.

Os neoliberais da década de 40 não encontraram condições favoráveis para o desenvolvimento de sua proposta, pois o capitalismo avançado estava entrando no auge, nas décadas de 50 e 60 . Eles desafiavam o consenso da época, ao denunciar a ordem social-democrata como um obstáculo à liberdade dos cidadãos e defender a desigualdade como um valor positivo.

As idéias neoliberais começam a ganhar terreno a partir de 1973, quando ocorre a grande crise do modelo econômico do pós-guerra: baixas taxas de crescimento com altas taxas de inflação. Instalou-se o início de uma longa e profunda recessão.

Para Hayek e seus seguidores, o motivo dessa crise era o excessivo poder dos sindicatos e dos movimentos operários, que através de suas pressões faziam com que o Estado aumentasse cada vez mais os gastos sociais. O remédio proposto para a mesma era manter um Estado forte em sua capacidade de romper com o poder dos sindicatos e controlar o dinheiro, e fraco em todos os gastos sociais e nas intervenções econômicas ${ }^{9}$.

A meta a ser atingida deveria ser a 
estabilidade financeira, cuja concretização implicaria disciplina orçamentária, com a contenção dos gastos com bem-estar; desemprego (exército de reserva para quebrar os sindicatos); reformas fiscais; e redução de impostos para os altos rendimentos.

As principais conseqüências da implantação de um programa neoliberal são "a deflação, a desmontagem de serviços públicos, as privatizações de empresas, o crescimento de capital corrupto e polarização social" (ANDERSON, 1995, p. 19), seguidas da ampliação das diferenças sociais e da quebra do aparato industrial.

Para Bóron (1995), o dogma neoliberal, a geração da pobreza é sinal de que se está indo no rumo certo. A geração do desemprego é um sinal de que as coisas caminham bem, de que a economia está se reestruturando, modernizando, tornando-se mais competitiva. A pobreza e o desemprego são nada mais que as dores do parto da nova sociedade que os feiticeiros neoliberais estão fazendo nascer e não há razões para se preocupar.

Genealogicamente, a primeira experiência neoliberal aconteceu no Chile, sob a ditadura de Pinochet. $\mathrm{O}$ neoliberalismo chileno pressupunha a abolição da democracia e a instalação de uma ditadura militar.

Concretamente, foi a Inglaterra, no governo Thatcher, o primeiro país capitalista avançado a pôr verdadeiramente em prática o programa neoliberal. Thatcher interrompeu o longo período de dominação hegemônica do Estado de Bem-Estar inglês, sua ideologia e suas práticas.

À experiência neoliberal inglesa seguiram-se outras: os Estados Unidos, com Reagan; em 1982, a Alemanha com Khol. Em seguida, quase todos os países do Norte da Europa Ocidental adotaram a política neoliberal.

Com a queda do comunismo na Europa Oriental e na União Soviética, o neoliberalismo também ganha terreno nessa área do continente. E a América Latina constitui-se na terceira grande cena de experimentações neoliberais. "Instala-se aqui, uma versão aguda do neoliberalismo, com ‘ajustes' muito mais drásticos do que os praticados nos capitalismos avançados" (LOPES, 1995, p.10).

A partir de 1989, após uma reunião entre funcionários do governo norte-americano e os organismos financeiros internacionais (FMI, Banco Mundial e BIRD), denominada de Consenso de Washington, define-se como condição para conceder cooperação financeira externa, bilateral ou multilateral a implantação da proposta neoliberal, enfatizando-se dois pontos básicos: redução do tamanho do

${ }^{9}$ Para o neoliberalismo, o Estado (setor público) é o responsável pela crise, pela ineficiência. O setor privado é sinônimo de eficiência, qualidade, eqüidade. Para chegar à eficiência é necessário que todos os direitos (conquistas sociais como a educação, saúde, transportes, empregos) sejam regidos pelas leis do mercado (MARTINS, 1997, p.143). 
Estado e abertura da economia.

No Brasil, com a eleição de Fernando Collor de Mello, em 1989, através de eleições diretas, inicia-se o combate aos gastos excessivos do Estado, utilizando-se como bodes expiatórios a má distribuição de renda, a situação depredada da saúde, da educação e de todas as políticas sociais.

A sociedade, por sua vez, responde ao ataque neoliberal tentando impedir seu avanço e Collor é destituído da presidência pelo Congresso Nacional, em 1992.

Com a eleição de Fernando Henrique Cardoso, a reedição do avanço neoliberal no Brasil se faz de forma muito mais eficiente. A idéia era propor e executar um plano de combate à hiperinflação e construir no imaginário das pessoas a perspectiva de uma era de estabilidade. O receituário do plano e sua letalidade tem duas facetas: enquanto a economia se recupera, o social piora.

Entretanto, a letalidade maior do neoliberalismo é a desesperança que se instalou e o medo da mudança, da reforma, da experimentação. Essas experiências demonstram que as políticas neoliberais, enquanto ideologia, alcançaram hegemonia.

Na opinião de Anderson (1995), qualquer balanço atual sobre o neoliberalismo só pode ser provisório, por este ser ainda um movimento inacabado. $\mathrm{O}$ que pode se realizar, por enquanto, é uma avaliação provisória dos seus 15 anos de implantação: economicamente, o neoliberalismo fracassou; socialmente, conseguiu muito de seus objetivos, criando sociedades mais desiguais, mas não tão desestatizadas; política e ideologicamente, o neoliberalismo alcançou êxito num grau com que os seus fundadores jamais sonharam: disseminou a idéia de que não há alternativas para os seus princípios; todos, aceitandoo ou não, têm de adaptar-se às suas normas, pois o mesmo tornou-se hegemônico e globalizado.

\subsubsection{Influências do Neolibera- lismo na Política Educa- cional}

Atualmente, existe um consenso em torno do projeto neoliberal que torna impossível pensar o econômico, o social e o político fora dos princípios que justificam e legitimam o modelo, o qual propõe uma confiança cega na dinâmica do mercado e um Estado mínimo ${ }^{10}$.

Nesse contexto, a educação novamente passa a ter um papel estratégico, servindo aos interesses empresariais e industriais, tal como no período militar na década de 70. De um lado, a educação institucionalizada passa a ser "preparadora" para o trabalho, formando mão-de-obra qualificada para a competitividade do mercado nacional e internacional. Essa redefinição

${ }^{10} \mathrm{Ou}$ seja, forte na sua capacidade de controle, e fraco em gastos sociais e intervenções econômicas. 
neoliberal da educação como treinamento tende a acentuar a dualidade do ensino, uma vez que os novos padrões se destinam a crianças e jovens das classes subalternas. Conseqüentemente, as classes com poder e recursos continuarão a reivindicar pedagogias e currículos que garantam um conhecimento técnico e científico de alto nível, assegurando a manutenção do "status quo". De outro lado, a educação passa a ser utilizada como veículo de disseminação e de reprodução da ideologia neoliberal.

Esse destaque dado à educação atualmente não é fortuito, considerando-se a demanda social na área educacional e, também, o consenso da gravidade dos problemas de ensino no país, que precisam de soluções para incorporar-se à nova ordem mundial.

Assim, competitividade, êxito, produtividade, mensurabilidade, aparecem como conceitos-chave e critérios de qualidade na lógica neoliberal e se constituem no novo senso comum dominante no que se refere à concepção de educação para este final de século, enquanto paradigma orientador das políticas educacionais de grande parte dos países latino-americanos.

Evidentemente, a estratégia neoliberal não se restringe ao campo educacional; ela se constitui num amplo processo de redefinição global dos setores social, político e pessoal, no qual mecanismos de legitimação são articulados em favor da disseminação de um clima favorável à visão social e política liberal.

No campo educacional, percebese a intenção neoliberal de reduzir as questões políticas à questões técnicas. Os problemas sociais e educacionais são tratados como questões meramente técnicas, relacionadas à eficácia/ ineficácia na gerência e administração de recursos humanos e materiais, não sendo considerado o seu caráter histórico de lutas e reivindicações.

Nessa linha de raciocínio, os inúmeros problemas enfrentados no cotidiano das escolas são vistos como decorrentes de uma má gestão, de um inadequado aproveitamento dos recursos públicos, da falta de produtividade dos professores e administradores, de métodos de ensino e de um currículo ultrapassados. Trata-se de arrumar soluções técnicas para problemas técnicos e a privatização do ensino é uma delas ${ }^{11}$.

O neoliberalismo propõe a privatização dos sistemas educativos, porque sustenta que a crise na educação só se resolverá através dela. Para os neoliberais, essa crise é produzida pela expansão desordenada e anárquica que os sistemas educativos sofreram nos últimos anos. É uma crise de qualidade, derivada da improdutividade que caracteriza as práticas pedagógicas, e da gestão administrativa na grande maioria dos estabele-

${ }^{11}$ Cf. SILVA, Tomaz Tadeu,1994. 
cimentos escolares. Para eles, não faltam escolas: faltam melhores escolas; não faltam professores: faltam professores mais qualificados; não faltam recursos econômicos para facilitar políticas que favoreçam a educação, só falta uma melhor distribuição dos recursos existentes. O problema está na administração e gestão, e não na democratização da escola.

Na perspectiva neoliberal, a escola funciona mal porque as pessoas não reconhecem o valor do conhecimento; os professores trabalham pouco e não se atualizam; os alunos fingem que estudam, quando na realidade perdem seu tempo. Trata-se de um problema cultural provocado pela ideologia dos direitos sociais.

A discussão a respeito da privatização efetivamente toma corpo e se acelera a partir da década de 90, especificamente com o início do governo Collor. Começase a tecer uma dura crítica à simples presença do Estado no campo educacional e a afirmar o mercado como solução para o enfrentamento dos graves problemas com os quais o país se defronta.

A diminuição da presença do Estado na área educacional vem sendo defendida há algum tempo e essa tese já circula em diversos segmentos da sociedade, cujos maiores defensores são os organismos internacionais (FMI, Banco Mundial e BIRD) que financiam projetos governamentais e apresentam suas diretrizes, recomendando que o Estado contente-se com o atendimento do ensino básico, deixando os demais níveis a cargo da iniciativa privada.

É parte essencial dessa estratégia apresentar as vantagens de um Estado mínimo e de menos governo. Assim, a estratégia liberal de desvincular a educação institucionalizada da esfera pública e submetê-la às leis do mercado significa mais controle e "governo" sobre a mesma, transformando-a num objeto de consumo individual e não de discussão pública e coletiva (SILVA, 1994, p. 35). Significa fazer a educação pública funcionar em analogia ao mercado.

O discurso da privatização está atrelado aos aspectos da produtividade, eficiência e qualidade ${ }^{12}$, sendo que a referida privatização, começa a ser teoricamente difundida no final da década de 80 , com a substituição do discurso da democratização, assumindo uma conotação própria do setor produtivo empresarial, com conseqüências dualizadoras e antidemocráticas, de cunho conservador.

As demandas pela democratização da educação surgiram em meados da década de 80 - período pós-ditato-

${ }^{12}$ Neste trabalho, produtividade, eficiência e qualidade não são termos da tendência tecnicista modelo fordista - mas, referem-se ao toyotismo - sistema de organização da produção, de relações interempresariais e de relações de trabalho desenvolvidos pela Toyota, indústria automobilística do Japão, considerado, por muitos, como superior ao fordismo. 
rial $^{13}$ - e tiveram representatividade durante um curto período. Em questão de uma década, a preocupação com a democratização deixou de ser o ponto principal a ser contemplado pelas políticas públicas do setor educacional, constituindo-se num tema esquecido no cenário das políticas educacionais.

Pelo próprio contexto de silenciamento da sociedade civil organizada, as ações em torno dessa demanda foram tornando-se inexpressivas, uma vez que, ao mesmo tempo, grande parte dos intelectuais progressistas deixaram o movimento arrefecer, diminuíram as produções acadêmicas em torno do tema e foi se esvaziando o seu conteúdo transformador. A intencionalidade política de parte dos intelectuais foi assemelhando-se cada vez mais ao discurso neoconservador.

Nesse contexto é que o debate em torno da democratização da educação nos países latino-americanos foi "substituído" pelo discurso da qualidade. Essa substituição não se justifica pela eliminação do problema, uma vez que os países da América Latina permanecem com altos índices de pobreza, marginalidade e exclusão social.

Num período de intensa ideolo- gização neoliberal em torno das categorias do sistema capitalista, aos mais diversos setores da sociedade, o discurso da qualidade foi desviado para o campo da "eficiência e produtividade", não demorando muito tempo para tornar-se hegemônico no meio empresarial. Assim, surgiu o programa "Escola de Qualidade Total" 14 .

A Escola de Qualidade Total começa a evidenciar-se como a tentativa mais séria de aplicar os princípios empresariais de controle de qualidade no campo pedagógico. A autora da proposta supõe que uma solução possível para a crise educacional do país reside na concepção de um modelo brasileiro de Escola de Qualidade Total (GENTILI, 1997, p.143).

O modelo de Qualidade Total para a educação, centrado nos princípios de gestão democrática, cidadania, produtividade, eficiência, liderança, comunicação e tecnologia, fecha qualquer possibilidade de se pensar a educação fora dos padrões empresariais/neoliberais, impondo uma concepção de educação total-

\footnotetext{
${ }^{13}$ Os governos civis pós-autoritários nos países latinos americanos têm sido - quase sem exceção - a continuidade dos regimes ditatoriais que os precederam. Segundo Perry Anderson (In: Gentili, 1997, p. 118), a democracia capitalista na América Latina é construída sobre a derrota das classes populares. Ainda, para ele, as ditaduras latino-americanas foram contra-revoluções preventivas cuja missão primordial foi a de decapitar e eliminar uma esquerda que não se resignava ao modo de produção capitalista, mas que apontava diretamente para um socialismo que o transcendia. ${ }^{14}$ Desenvolvido no Brasil por Cosete Ramos, Coordenadora Adjunta do Núcleo Central de Qualidade e Produtividade, subordinado ao Ministério da Educação.
} 
mente voltada para o modelo de gerência educacional.

Segundo a lógica do modelo de Qualidade Total para a educação, a centralização administrativa é um ranso que se constitui como barreira para a qualidade. Assim, a descentralização aparece como transferência do poder do Estado para a comunidade.

De acordo com o neoliberalismo, a atividade econômica deve ser estimulada e liberta de controles. A sociedade civil surge como novo ator social, decidindo localmente a respeito de problemas comuns, livres de interferências. Ao tentar-se analisar a real intenção do Estado, ver-se-á que existe um enorme perigo deste "imitar Pilatos", transferindo encargos para a comunidade no que tange à gestão educacional.

Basicamente, quando ocorre a descentralização, o Estado desresponsabiliza-se: os municípios mais pobres vêem-se obrigados a obter recursos na própria comunidade, para manter a escola. Esta é uma forma de privatizar a escola, na medida em que é a sociedade civil que tem a incumbência de manter a responsabilidade que o Estado delegou ao município e este à sociedade.

A transferência de recursos diretamente para as escolas parece apontar para a autonomia escolar mas, na prática, pode vir a apresentar problemas, dada a sua complexidade. Cabe aqui indagar o seguinte: se o governo federal tem dificuldades em proceder re- passes de recursos para os Estados e municípios em tempo hábil, o que dizer de transferências diretas para as escolas?

Outra tendência que se observa na política neoliberal para a educação é a priorização do ensino básico, em detrimento do ensino superior. O maior defensor dessa proposta é o Banco Mundial, que sustenta que os recursos são escassos e que todo país deve realocar os recursos públicos da educação superior e técnica para a educação básica. "Básica" no que se refere à base de conhecimentos (leitura, escrita, matemática, solução de problemas) e à sua identificação com os primeiros anos de escolaridade.

Para o Banco, essa estratégia satisfaz o objetivo de reduzir a pobreza, porque os pobres dificilmente podem freqüentar o ensino fundamental, e é nesse nível que se concentrará a maior parcela dos recursos. O acesso à educação básica propicia o aproveitamento do principal recurso dos pobres, que é sua capacidade de trabalho, que aumenta com a educação, contribuindo para a formação de trabalhadores mais flexíveis, que possam facilmente adquirir novas habilidades.

Corraggio (1996) destaca que o aumento da renda de uma pessoa analfabeta seria proporcionalmente maior que o aumento de salário de um profissional com pós-graduação, em cuja educação adicional fosse investido o mesmo montante. Assim, 
o investimento na educação primária traria mais vantagens sociais do que na secundária e na superior. A hipótese é de que a vantagem "social" coincidiria com a vantagem dos setores mais carentes.

Analisando especificamente o contexto paranaense, a partir da década de 80 , são observadas as primeiras nuances do neoliberalismo na política educacional do Estado. Os últimos governos vêm imprimindo propostas e ações atreladas aos princípios neoliberais, que enfatizam o deslocamento de enfoques: da quantidade para a qualidade; da centralização para a descentralização; do público para o privado; do ensino superior para a educação básica; e das questões políticas para as questões pedagógicas.

Em 1982, com a vitória do PMDB - partido oposicionista ${ }^{15}$-, o governo imprimiu em seu programa a diretriz "Democracia e Justiça Social". Essa democratização deu-se sob a forma de participação comunitária, através de entidades representativas. A interação Estado - sociedade baseou-se na proposta de descentralização da máquina administrativa. Dessa forma, foram criados os Núcleos Regionais de Educação - NREs, centrados nas idéias de descentralização e participação popular.
Ainda nesse período iníciou o processo de municipalização do Ensino Fundamental, ou seja, a transferência das responsabilidades do Ensino Básico, do Estado para os municípios. Isso se fez através de um Protocolo de Intenções, que previu a contratação dos chamados "professores conveniados". Desde então, a municipalização vem ocorrendo gradativamente, atingindo a maioria dos municípios.

O princípio de re-democratização, ocorrido na sociedade civil através das eleições diretas, também teve seus reflexos na escola, com a eleição de diretores. Intensificou-se a importância das Associações de Pais e Mestres - APMs, que passaram a ser vistas com o objetivo de controlar e fiscalizar os serviços educacionais.

$\mathrm{Na}$ segunda gestão do PMDB no Paraná (1987-1990), foi implantada a proposta do Ciclo Básico de Alfabetização, com o objetivo de evitar a evasão e a repetência nas séries iniciais no ensino fundamental. Para a concretização dessa proposta efetivou-se a capacitação dos professores dos Cursos de Magistério, Ensino Fundamental e Médio, e também a implantação do Currículo Básico, procedendo-se às reformulações curriculares dos referidos níveis.

A gestão 1991-1994 foi marcada

${ }^{15}$ O Estado do Paraná foi governado por 12 anos consecutivos pelo Partido do Movimento Democrático Brasileiro - PMDB, momento em que a política educacional começou a sofrer alterações mais significativas. Compreende os governos: José Richa (1983-1986); Álvaro Dias (1987-1990); Roberto Requião (1991-1994). 
por um ideário que tenta conjugar, modernidade, eficiência, gestão democrática e participação comunitária. Na relação Estado-municípios se propôs a descentralização das ações pedagógicas, oferecendo-se maior autonomia às escolas. Deu-se a implantação do projeto político pedagógico em cada unidade escolar (Projeto Escola Cidadã), a criação dos Conselhos Escolares e Regimento Escolar Único.

No período de 1995 a 1998 (Governo Jaime Lerner), a ênfase foi dada à valorização do profíssional da educação com a criação da Universidade do Professor ${ }^{16}$, do Programa ValeSaber ${ }^{17}$, do Prêmio de Excelência de Desempenho da Escola, do Curso de Magistério para Professores Leigos, ao acompanhamento do Plano Decenal da Educação e à introdução da informática no Currículo da Educação Básica.

O que se observa no Paraná, a partir de 1982, a exemplo da conjuntura nacional, é que alguns avanços conquistados pela sociedade e pelos professores vêm sendo fragilizados. Nesse processo, assiste-se a uma contínua desconstrução da escola pública no plano da administração estatal.

\section{Considerações Finais}

A partir do estudo das diversas formas de Estado que se sucederam, observa-se que desde o mundo moderno até os dias atuais as suas transformações acompanharam as da sociedade civil e nenhum projeto hegemônico conseguiu se perpetuar, embora, em cada época, os projetos elaborados, tivessem a pretensão de ser a única resposta. Isso aponta para uma possibilidade de superação da forma de Estado atual (neoliberal) e suas sérias conseqüências econômicas, sociais e políticas ${ }^{18}$.

As políticas sociais já assumiram características diferentes das defrontadas atualmente: foram consideradas assistencialistas no período monárquico, parternalistas na corrente liberal e o que hoje se vê é o governo transferindo suas responsabilidades a diversos setores da sociedade, e os cidadãos perdendo o direito a conquis-

\footnotetext{
${ }^{16}$ A Universidade do Professor situa-se em Faxinal do Céu, no município de Pinhão - PR ${ }^{17}$ O Vale Saber é um projeto criado em 1995, que concede uma bolsa auxílio no valor de R\$ 100,00 ao mês, aos professores da rede pública e estadual de ensino que atuam em sala de aula nas modalidades de Ensino Fundamental e Médio. Essa concessão é dada aos professores que elaboram uma proposta de ação pedagógica definida nas formas de: Investigação Pedagógica ou Estudo Independente ou Qualificação Formal. A mesma deverá ser acompanhada por um professor orientador técnico-pedagógico das Instituições de Ensino Superior - IES.

${ }^{18}$ Sugere-se um aprofundamento teórico e empírico sobre as políticas pós-neoliberais, com o intuito de descortinar possibilidades de construção de um novo projeto social e educacional alternativo, voltado para a defesa dos direitos individuais e sociais, econômicos, políticos e culturais dos menos favorecidos.
} 
tas, como educação, transporte, emprego, saúde, etc. No neoliberalismo o paternalismo permanece, mas numa situação muito mais drástica, porque o Estado diminuiu seus gastos sociais e aumentou seu controle político.

Refletindo sobre as políticas educacionais, é possível perceber seus avanços e recuos, suas continuidades e descontinuidades, que submetem a educação ao poder auto-regulador do Estado, hoje fortemente atrelado aos interesses econômicos dos organismos internacionais, principais defensores do projeto neoliberal.

Esse contexto de reflexões remete a vários questionamentos: Como atuar diante de um compromisso ético e político para a formação do cidadão do terceiro milênio? Quais as razões de tantas propostas e projetos educacionais? De que forma justificar a descontinuidade das políticas educacionais nas mudanças de governo? É possível estabelecer um projeto radical de mudança que contemple as populações carentes?

Tais indagações possibilitam perceber que um dos avanços a ser destacado é a análise da política educacional no contexto das políticas públicas, ocorrido a partir do momento em que a sociedade civil começa a vivenciar o processo de democratização participando dos debates sobre os problemas sociais e educacionais.

Com essa postura a sociedade civil passa a constituir-se numa força política, não ficando submetida totalmente aos mandos e desmandos do
Estado. Na medida em que ela, via grupos organizados, tem a possibilidade de exercer a análise crítica do contexto em que está inserida, pode interferir nas transformações do modo de produção capitalista. A luta pela democracia e a ativação de espaços públicos começa na sociedade civil e não no Estado. É luta não excludente, em que ambos podem unir-se.

Os movimentos sociais representaram essa força política e foram um dos elementos que propiciaram a transição do processo político entre 1978 e 1985, constituindo-se como fator que apontou para a transformação social, porque neles havia uma promessa de renovação da vida política. Pode-se citar como exemplos desse processo, o Movimento em Defesa da Escola Pública, as reivindicações de piso salarial, autonomia, quadro de carreira; além daqueles movimentos externos à escola - de negros, das mulheres, índios, ambientalistas, dentre outros. O conjunto das atividades desses movimentos da sociedade civil contribuíram para a construção de um novo cenário, para novas formas de organização, destacando-se dentre elas as Organizações Não Governamentais - ONGs, partidos políticos e organizações sindicais, visando à defesa dos direitos individuais e sociais, econômicos, políticos e culturais dos oprimidos.

É importante que os profissionais da educação, enquanto atores sociais, estejam atentos às Políticas Educacionais e seus intervenientes, uma vez que 
as mesmas não consistem apenas num discurso teórico, mas numa ação que se revela em intenções, algumas vezes claras e visíveis; outras, obscuras e camufladas. Como a Política Educacional se refere à educação como um todo e não está circunscrita somente ao espaço escolar, é imprescindível, também, que os educadores percebam as contribuições que os movimentos sociais podem trazer para a escola e para a sociedade como um todo.

Isso pressupõe que os educadores, enquanto cidadãos de uma nova época, explicitem os propósitos que definem a intencionalidade e a dimensão das transformações necessárias no ambiente escolar, a fim de que sua atuação não se restrinja a legitimar políticas, programas oficiais ou simples inovações metodológicas que atingem apenas o âmbito da sala de aula, sem preocupação com um projeto maior - o de comprometimento com a formação de cidadãos pensantes e criativos.

Nesse sentido, destaca-se a necessidade de novas práticas políticas e de novos anúncios, porque a realidade continua sendo injusta e dura com os menos favorecidos. A realidade também tem mudado e novos velhos discursos, novas velhas práticas políticas são hoje pouco convincentes para as grandes massas que sofrem as conseqüências da exclusão, a morte da esperança e a desintegração de suas próprias vidas.

\section{REFERÊNCIAS}

\section{BIBLIOGRÁFICAS}

1 ANDERSON, Perry. Balanço do Neoliberalismo. In: GENTILI, Pablo; SADER, Emir (Orgs.). Pós-Neoliberalismo: As políticas sociais e o estado democrático. Rio de Janeiro: Paz e Terra, 1995. p.09-23.

2 ARANHA, Maria Lúcia de Arruda; MARTINS, Maria Helena Pires. Filosofando: introdução à filosofia. São Paulo: Moderna, 1986.

3 BÓRON, Atílio. A sociedade civil depois do dilúvio neoliberal. In: GENTILI, Pablo; SADER, Emir (Orgs.). Pós-Neoliberalismo: as políticas e o estado democrático. Rio de Janeiro: Paz e Terra. 1995 p.63-118.

4 CARNOY, Martin. Estado e teoria política. Campinas, SP: Papirus, 1986. 339p.

5 CHAUÍ, Marilena. Convite à filosofia. 6.ed. São Paulo: Ática, 1995.

6 CORRAGGIO, José Luis. Propostas do Banco Mundial para a educação: sentido oculto ou problemas de concepção? In: TOMMASI, Lívia de; WARDE, Mirian Jorge; HADDAD (Orgs.). O Banco Mundial e as políticas educacionais. São Paulo: Cortez, 1996. p.75-123.

7 COTRIM, Gilberto. Fundamentos da filosofia: ser, saber e fazer. 13. ed. São Paulo: Saraiva, 1997.

8 DAGNINO, Evelina. Os movimen- 
tos sociais e a emergência de uma nova noção de cidadania. In: DAGNINO, Evelina (org.). Anos 90: política e sociedade no Brasil. São Paulo: Brasiliense, 1994.

9 DEBRAY, Régis. O Estado sedutor: as revoluções midiológicas do poder. Petrópolis: Vozes, 1994.

10 FERREIRA, Pedro Roberto. Política e sociedade: as formas de Estado. In: TOMAZI, Darcio Nelson. Iniciação à sociologia. São Paulo: Atual, 1993. p.123143.

11 FREITAG, Bárbara. Política educacional e indústria cultural. São Paulo: Cortez, 1987.

12 GENTILLI, Pablo. SILVA, Tomaz Tadeu da (Orgs). Neoliberalismo, qualidade total e educação. 5 ed. Petrópolis, RJ: Vozes, 1997. p.111-177.

13 LOPES, Roseli Esquerdo. Neoliberalismo e políticas públicas de saúde no Brasil. Revista do Grupo de Estudos sobre Movimentos Sociais. Campinas-SP, n. 1, maio/1995. p.1-19.

14 MARTINS, Rosilda Baron. Escola Cidadã do Paraná: análise de seus avanços e retrocessos. Tese (Doutorado em Administração e Supervisão Escolar). Universidade Estadual de Campinas - SP, 1997.

15 NIELSEN NETO, Henrique. Fi- losofia básica. 3.ed. São Paulo: Atual, 1986.

16 SILVA, Tomaz Tadeu da. A "nova direita" e as transformações na pedagogia da política e na política da pedagogia. In: Paixão de Aprender. Porto Alegre, n.7, p.30-41, jun.1994.

17 TORRES, Carlos Alberto. Estado, Privatização e política educacional: elementos para uma crítica do neoliberalismo. In: GENTILI, Pablo (Org.). Pedagogia da exclusão: crítica ao neoliberalismo em educação. Petrópolis, RJ: Vozes, 1995. p.109-136. 